\title{
Reengineering Production Systems: the Royal Netherlands Naval Dockyard
}

W.H.M. Zijm, Dept. of Mechanical Engineering, University of Twente, Enschede, The Netherlands

Submitted by H.J.J. Kals (1)

Received on January 8, 1996

\begin{abstract}
Reengineering production syslems in an attempl to meet tight cost, quality and leadtime standards has received considerable attention in the last decade. In this paper, we discuss the reengineering process at the Royal Netherlands Naval Dockyard. The process starts with a characterisation and a careful analysis of the production system and the set of objectives to be pursued. Next, a new production management struclure is defined after which supporting planning and control systems are designed and a number of organisational changes are carried through. In this way, the Dockyard may combine high technological capabilities with an excellent logistic performance.
\end{abstract}

Keywords

Engineering, Production system, Maintenance

\section{Introduction}

Production system reengineering can be defined as a radical redesign of production systems 10 meet tight performance targets in terms of cost, quality, leadtime and flexibility. As such, it may be viewed as a part of the broader concept of business process reengineering, cl. Hammer and Champy (1). Such a reengineering process often leads to a more product-focussed organisation, as opposed to the functional organisations which have dominaled Western production since Adam Smith outlined the basic principles of labor division. A careful analysis of current production practice and a (new) sel of objectives forms the basis of any redesign. Based on this, a new production management structure has to be defined and supporting organisational structures and planning systems need to be developed.

In this paper, we sketch the basic elements of a reengineering process carried out at the Dockyard of the Royal Nelherlands Navy. located close to the city of Den Helder in the north-westem part of Holland. A "production reengineering project leam", consisting of members of the Dockyard management and researchers of the University of Twente, was established in early 1994. The goal was to design a new production management structure for the Dockyard and to develop protolypes of a new process planning, as well as an intelligent production planning and control system. In addition, organisational consequences had to be clarified. In the nexl section, we start with a brief history of the Dockyard and sketch its main activilies, as well as the new objectives and constraints it is faced with. In subsequent sections, a lypology of the production processes at the Dockyard is discussed, a number of current deficiencies are highlighted and a new production management structure, including a work breakdown structure, is defined. Next, we briefly describe supporting systems needed for process planning, capacity management and materials control, as well as some organisational changes.

The project team has been given four years to complete ils work; therefore the work reported in this paper is part of a still ongoing activity. Nevertheless, major concepts that are to form the new production management structure have been defined by now while several supporting tools are currently under development. This paper reports on the results obtained so far. Due to the military character of the production environment, technical details on ship production and maintenance are omitted.

\section{The Royal Netherlands Naval Dockyard}

The Dockyard of the Royal Netherlands Navy (RNN) was eslablished in 1822 by King William I under the name of "Willemsoord", to meet the Dutch navy's need for its own wharf in the north of the country. In that same century the wharf developed itself into one of the largest industrial enterprises in the Netherlands. Within the spectra of last technological developments, from the wooden sailing ships into the present day composite frigates, the Dockyard has worked and continued to work on the frontiers of technology. In 1992, a brand new shipyard was opened at the harbor yard of the RNN, resulting now in the most modem and well equipped maintenance and repair service for Naval ships in Western Europe.

The main lask of the Dockyard is to provide in the need for mainlenance, repair and modification of platform systems on board of the ships of the RNN, as well as many shore facilities. Platform systems of a ship are defined as the hull, the propulsion system, energy supply system, climate control system, etc. All sensor, weapon and command systems are maintained by a second maintenance establishment, the SEWACO company.

The maintenance of ships themselves can be divided into four calegories. We distinguish lorĩg lerm maintenance (LTM, involving a major overhaul and modification program. once every six years and lasting up to a year for large frigales), between time maintenance (BTM, involving a moderate overhaul every six years, without modifications. halfway between two LTM's and laking up to three months) and appointed incidental maintenance (AIM, a few times each year, with a mean duration of a couple of weeks). 
These three types of appointed maintenance take place in prespecified periods. Apart from these three categories, we find incidental maintenance (IM), defined as corrective maintenance which cannol wait for a forthcoming appointed maintenance period. Modifications may involve minor construction works up to building complete new ship's sections.

The Naval Dockyard can be characterized as a functional organization, consisting of several departments of which the two most important ones are the Department of Technology. including Maintenance Engineering, and the Production Department. The latter actually carries out all maintenance activities whereas Maintenance Engineering provides technical support. The Production Department comprises amongst other things three divisions (Capital ships, MineCounter Measures service and Submarine service) which form the contact with the three main client groups, and four working fields: shipconstruction 1 and 2, mechanical and electrical engineering. Each working field finally consists of a number of expertise groups.

The above sketched functional organization reflects the strong technological orientation of a dockyard. equipped to serve the most advanced technological systems available in the Navy to dale. At the same time however, such a structure prohibits a smooth and flexible, client-oriented logistic performance. These drawbacks became painfully clear when. as a result of international developments and subsequent political decisions, maintenance budgets were drastically cul and worklorce was downsized from 1800 to slightly more than 1000 people within a period of ten years. Finally, corrective mainlenance by definition may be somewhat unpredictable with respect to capacity and materials needed, hence requires quite some flexibibity of the maintenance organisation. In practice, the Dockyard's delivery performance, in particular for LTM's and BTM's, tended to become worse and worse; due dates were seriously exceeded, or met at tremendous extra costs of overtime work and subcontracting. Similar to many industrial companies faced with changing circumstances, a new production structure became inevitable for the Dockyard. After several preliminary investigations, the senior Dockyard management decided to fundamentally redesign all maintenance engineering and production processes, involving both work organisation and production planning and control.

\section{A typology of the production system}

A basic typology of discrete production processes (see e.g. Fogarty et al., 2) distinguishes flow shop, job shop and fixed site (project) production. While flow shop production in principle describes the situation of moderate to large batch (serial) production (often assembly), job shop production generally represents small balch parts manulacturing while project work often involves one-of-a-kind production. A careful analysis of the work package of the Naval Dockyard (cl. De Waard, 3) revealed that almost all work falls within the latter two categories: much repair and overhaul work is necessarily carried out on board while furthermore (sub)systems may be disassembled and transported to the workshop for either repair or revision, after which they are retumed to the ship for assembly again. Any modification (which somelimes involves the construction of complele new ship segments) is necessarily an activity on the site again. Most activities on board have to be performed within severe time and space limits and are subject to precedence constraints. Finally, much work is either unique or has a low repetition factor. Therefore. in principle the overhaul of a ship (in particular the LTM's and BTM's) should be considered to be a project.

As mentioned already, some work on ship installations is carried out in specialized work shops. In addition, the Dockyard has the option to replace a subsystem or component by an alternative one (which had been stored as a "ready for use" item) and delay the repair of the removed one. This repair by replacement option can be used to unload critical capacity botllenecks or simply for elficiency reasons. The removed, malfunctioning component or subsystem is repaired or revised at some later time (at the Dockyard) and nexl slored as a ready for use ilem again. This illustrates the close relation belween capacity management and materials planning, in particular for repairable items. Finally, recall that the Dockyard is also responsible for the maintenance of all shore establishments of the RNN which oflen is work of a job shop character again.

A detailed analysis (3) indicales that about $60 \%$ of the work bears a project characier. In the sequel, we concentrate on this part of the work. Note that we may consider the Dockyard as a multi-project production system in which limited resources (personnel, docks, a ship lift complex) have to be shared by multiple ships.

\section{A new production management mode!}

When we started the production reengineering project in early 1994, a large number of deficiences in current operations praclice were listed. For instance, work acceplance and preparation procedures were not very clearly defined. As a resull, work was often accepted withoul checking for sufficient capacily of critical expertise groups. In addition, a rough nelwork plan was already designed while much of the process planning (work preparation) activilies still had to be carried out, causing parts of the designed network to be totally useless. Material planning was separated from the network planning activities. Documentation and coding of maintenance procedures appeared to be messy, therefore retrieval of necessary information for process planning was hard, if possible at all. Many process planners therefore used their own personal note books to prepare activities. All NATO coded items had to be ordered from a separate Naval Logistics Centre (not under control of the Dockyard) which often caused additional delays. The primarily technological view of the engineering department did not always support the logistic objectives pursued by production (as is still the case in many companies). Production itself still worked according to internal efficiency ralher than external effectiveness: work was clustered primarily according to specialisalion needed, instead of dependent on project related precedence relations. As a result, many activities could not start due to uncompleted preceding work. Below, we will return to this issue. 
The above observations and the lypology of the Dockyard's activities presented in Section 3 have led to a series of actions. With respect to the project-oriented part of the work, a new 4-step production management model has been defined. Before discussing it, we define a new work breakdown struclure. As mentioned, tasks within a project were often clustered if they could be carried out by one expertise group, no matter whether these tasks concerned entirely different installations on a ship. In this way. precedence relations of tasks concerning the same installation were ignored in favor of a presumed expertise group efficiency. Obviously, such a way of work structuring inevitably leads to coordination problems: maintenance workers who could not start their job and had to wait or return later, resulting in both inefficiencies and due date problems. An alternative. installation based, work breakdown structure is displayed in Figure 1. Here a project (a complete ship's overhaul) is decomposed into a number

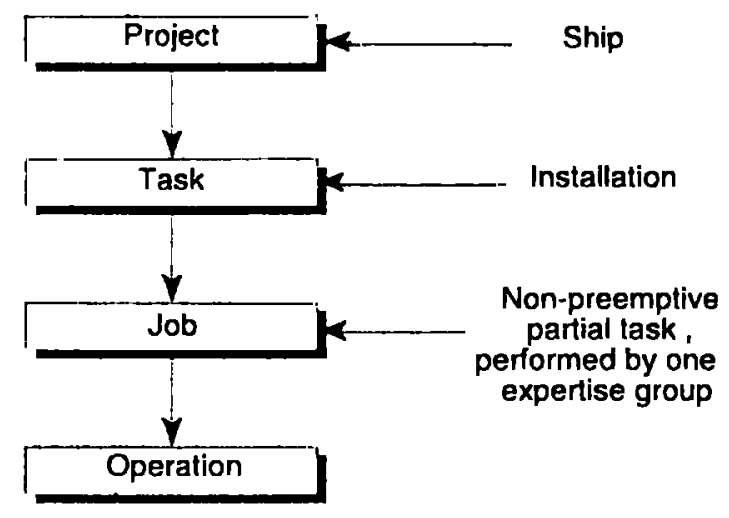

Figure 1. A new work breakdown structure

of maintenance tasks where each task represents maintenance of one complete installation or well-delined ship segment. A lask is further decomposed into a sequence of jobs, where a job is defined as the largest part of a task which can be performed uninterrupted by one expertise group. Finally. jobs may be decomposed into operations, each of which may require a sel of work instructions.

Next, we briefly outline the four steps of the production management model (see Figure 2).

a. Order acceptance. Long-term overhauls as well as modifications are often scheduled long before a ship arrives at the Dockyard. Requests for corrective maintenance (repairs) can be passed to the Dockyard not later than four weeks before the ship arrives; at that point in time the maintenance list is closed.. This does not mean that all work is fully specified: in particular in case of disturbances a carelul diagnosis (often by means of an expert survey) is needed before preparatory aclivities at the harbor can even start. Based on the mainlenance list, technical standards (estimated durations of repair and overhaul tasks) and additional surveys, a rough cut capacily planning (RCCP) is made for each expertise group. This evaluation permits to decide upon work acceplance and, if needed, on subcontracting actions.

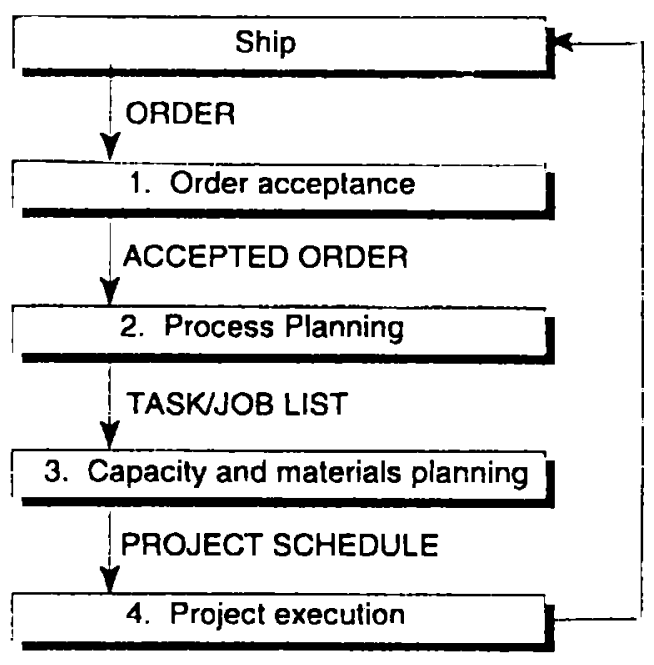

Figure 2. Production Management Model

b. Process Planning. During the process planning phase, all mainlenance lasks (repair, overhaul and modifications) are worked out in detail. In case of modifications, assistance from maintenance engineering is needed. In all cases, the result of the process planning procedure is a detailed joblist, as well as a list of materials and resources (manpower and facilities) needed. At the most detailed operations level, work instructions, drawings, etc. should be provided. All jobs are placed in a (so far, uncapacilated) network to specily precedence relations (Figure 3 ). This should not be confused with network planning which is part of the third step. To facilitate the process planning activities, a relational database system has been developed (Section 5).

c. Capacity and materials planning. Based on the network of jobs and the list of resources and materials, needed for each job, which result from the process planning phase, these jobs should be scheduled in time, given the limited availability of resources, and materials have to be ordered. At this point, the malrix organisation of the Dockyard comes to light; projects, each needing capacity from a variety of resources and each bounded by sometimes tight time constraints, compete with each other for the limiled availability of these resources (expertise groups, docks, a ship lift system). To this end, a multi-project capacity planning syslem has been developed. This system will be briefly discussed in the next section. In addition, an appropriate materials planning system is still under development.

d. Project execution. Each project is under supervision of a project manager (to be discussed in Section 6). He releases jobs while all completed jobs are reported to him again. The project manager is also responsible for the availability of an means, tools and materials to complete any job in time. Of utmost importance is an accurate time registration of all jobs to further maintain and improve the process planning database system. 


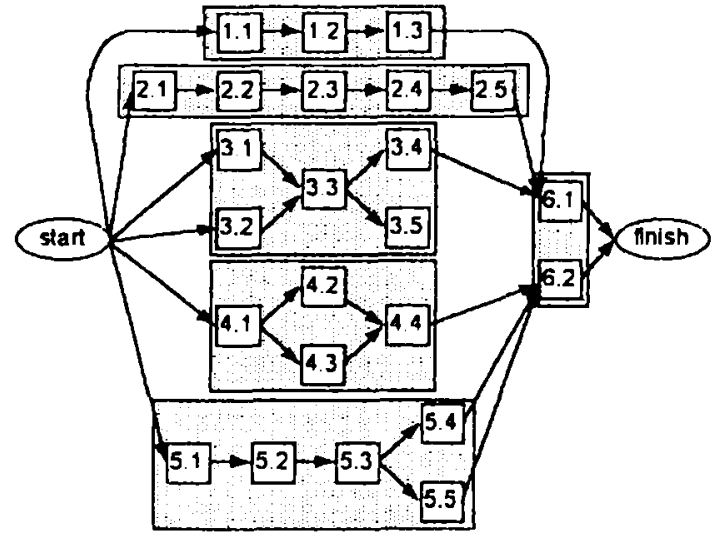

Figure 3. Project network

Although the above skelched production management model may seem quite nalural, it is already far from current practice (recall the introduction to this section). Also, it is clear that the model above remains abstract without adequate supporting tools, in particular for the first three steps. As mentioned earlier, process planning needs a properly designed relational database, specifying slandard repair and overhaul activities at task, job and operation level. Multi-project capacity planning is well-known for its complexity and intelligent support tools are badly needed. The same holds for materials planning. We emphasize that these requirements go far beyond the capabilities of Manufacturing Resources Planning systems (cf. Wight, 4), which are merely sophisticaled information systems but lack intelligent planning and scheduling procedures and often lead to a rather rigid organisation structure.

This sketch of a new production management structure is not complete without discussing the so-called portfolio management level (see Figure 4). This level has been defined to solve possible conflicts arising from the competition of different projecls for the same limited resources. The capacily planning system to be discussed in the next section has been designed in such a way that possible conflicts are signalled as early as possible. Furthemore, within the total capacity constraints, "close to optimal" solutions are proposed which however may lead to tardiness of certain projects. If the final result remains unacceptable, all project and expertise group managers meet with a portfolio manager to reach agreement upon alternative actlons (overwork, subcontracling, repair by replacement, delay or modification of certain tasks, etc.). This porffolio management level plays an extremely important role in multi-project production control.

This concludes our presentation of the basic production management model. In the next section we shed some light on the Decision Support Systerns needed.

\section{Developing Decision Support Systems}

In this section, we discuss in particular the development of a database syslem for process planning and a multi-project capacily planning and scheduling system. As mentioned earlier, basic slandards needed for process planning often could not be retrieved, did not exist or were totally unreliable. This was completely unacceptable: irrespective of what organisation or production planning and control system should be developed, good standards are needed anyhow. Therefore, a major effort has been undertaken to design a completely new relational database system; at this time, a number of process planners spend most of their time in filling the system.

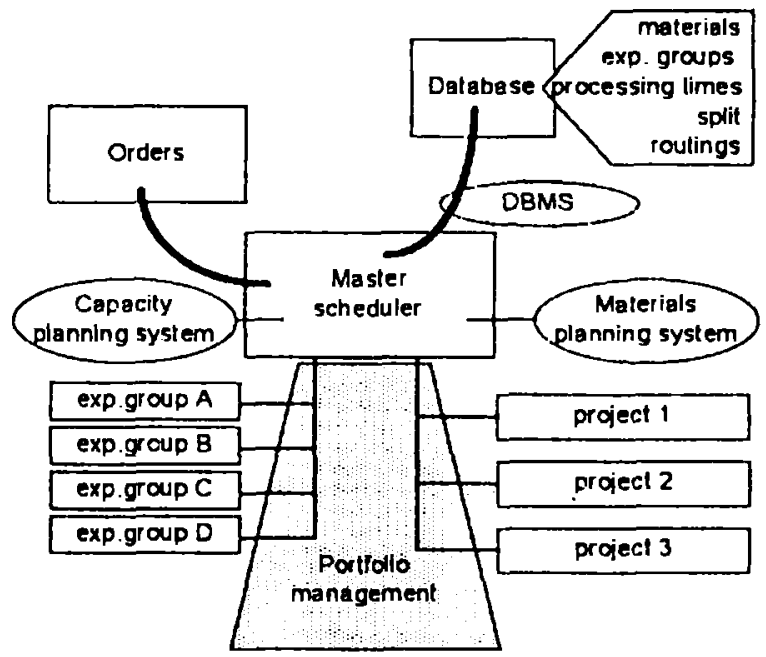

Figure 4. The role of Portfolio Management

For reasons of conlidentiality, we are not allowed to discuss the system in detail. Its structure is the usual one for such systems: the database ilself, a database management system and a number of application programs. It is based on the work breakdown structure described in the preceding section and uses an extended version of a coding system already in use for the Navy's installations, sub-syslems, etc. The application programs enable the use of the database at job-, task- and operation level, to facilitate rough cut capacity planning for order acceptance, capacily scheduling and detailed process planning, respectively (see Figure 5 and Groenestein, 5).

Another development concerns the capacity planning and scheduling system. Earlier, we mentioned the complexity of multi-project scheduling under both capacily and time constraints. A new scheduling system has been developed at the University of Twente, based on a mixture of lechniques of which simulated annealing and the so-called shifting boltleneck decomposition approach form the basis. The latter technique (cf. Adams el al., 6, and Zijm, 7) was initially developed for scheduling in complex machine shops but has been extended to cope with multiple resource groups, each of which can be split in order to handle a number of jobs simultaneously (see also De Boer and Zijm, 8). The system presents graphical overviews (Gantt Chants) with respect to both projects and expertise groups while unsolvable conflicls are visualized and presented at the portiolio management level. The capacitated networks that result from the scheduling system allow for some flexibility by specifying time windows for each job, instead of strict start and finish times. Since in particular repair lasks may 
be subject to uncertainty (an accurate diagnosis in advance is not always possible), these time windows provide some necessary flexibility. Figure 6 shows the different views provided by the scheduling syslem.

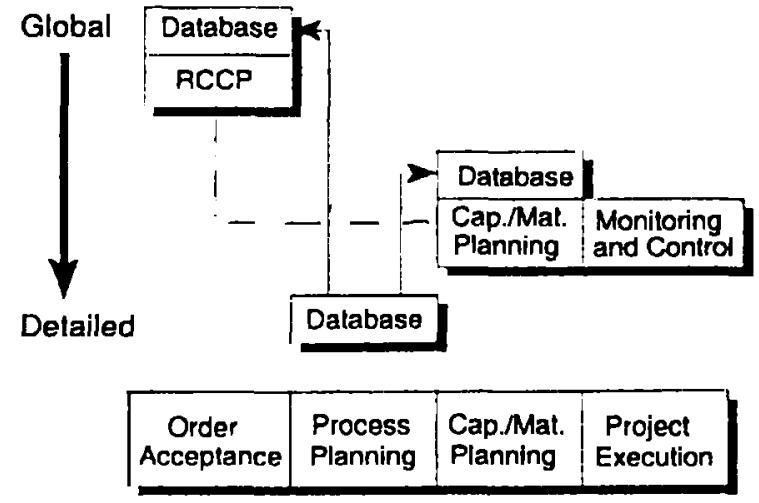

Figure 5. Use of process planning database at various levels

The start of the time window for each job also specifies the time at which materials have to be available. Usually, a safety leadtime is taken into account or materials should be available before the start of a full task. If a malerial or part cannot be delivered in time this delays the starting time of the activity, unless emergency actions can be undertaken. It will be clear that a sophisticated inventory management system, in particular for repairable items, will be a key condition. Inventory management at the Naval Logistics Centre is given special attention via a second project, aiming at the development of such a system. Fortunately, much work in this field has been done, in particular for the US Navy and US Air Force (see e.g. Clark, 9).

\section{Further organisational changes}

As mentioned already earlier, a major part of the Dockyard's work bears a project character. Recognizing this, and realising the importance of the timely completion of projecls, it becomes clear that each project should be supervised by a project manager with full responsibility. Up to now, project coordinators were already functioning at the Dockyard but their authority was limited and often they were subject to late decisions of expertise group managers on the number of personnel they could get. Also, these coordinators did not have any influence on the amount of work to be done since work was accepled elsewhere, often without a proper check on the availability of sufficient expertise group capacity.

One further important organisational change concems the merge ol production and maintenance engineering in one department. Although it is recognised that maintenance engineering has also tasks not directly relaled to operational production (such as defining maintenance standards and procedures) its most important lask is undeniably to support production in carrying out its primary task, to maintain the ships in the highest operational condition. Although this seems obvious, until recently process planning was performed by a group of process planners within the production department, while maintenance engineering was only consulted in case of modifications or in case problems arose which could not be solved by production itself. This seems to be quite a waste of expertise knowledge. Nevertheless, the different cullures of the former two departments still cause difficulties in accepting the new structure.

Recently, the decision has been made 10 bring also the Naval Logistics Centre under direct control of the Dockyard. This means that the Dockyard is now responsible for inventory policies with respect to repairable items. Recall that the Naval Logistics Centre requests the Dockyard to repair or revise all parts or subsystems that were removed in a "repair by replacement" action. Once the Dockyard has responsibility for all stocks of repairable items, it becomes easier to reserve parts of its total capacity to this repair work (not connected with a project at a ship) and give il appropriate priority. Again, this seems obvious but one should realise that the Logistics Centre is also responsible for the supply of all comsumable articles to the fleet. The new situation places the Dockyard in the role of full supplier of the ships.

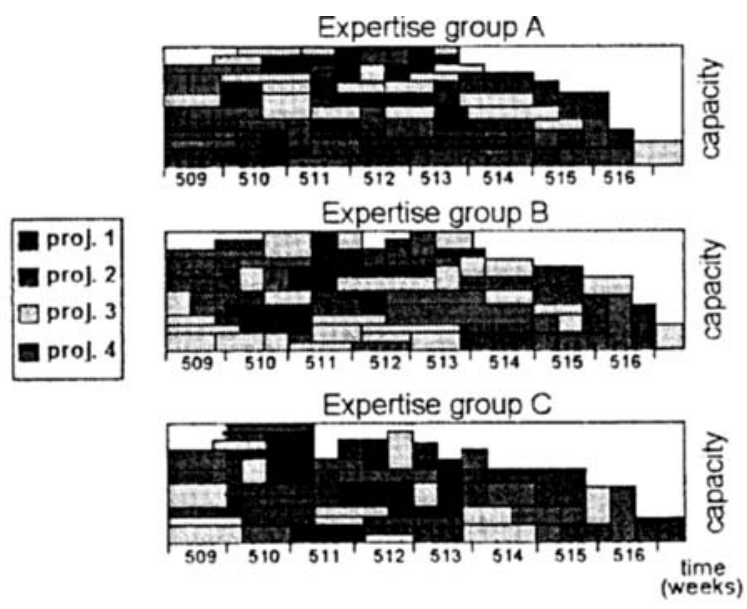

Figure 6.a. Capacity view for Expertise group managers

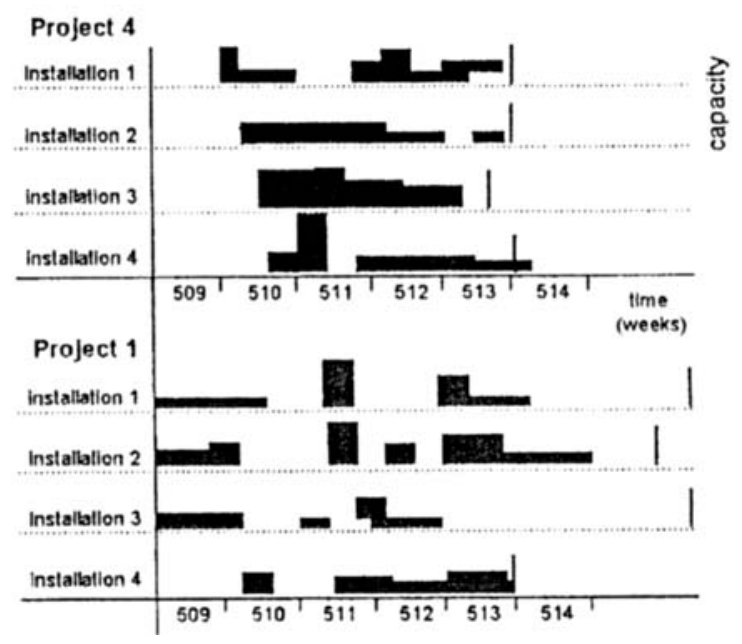

Figure 6.b. Planning view for Project managers 
A final, but highly important topic still under research is the possible introduction of teams fully responsible for the maintenance of one or more ships, i.e. a grouptechnological produclion approach (cf. Burbidge, 10). Such an approach often leads to a serious reduction of overall planning complexily (cl. Wiendahl and Scholtissek, 11); in our case, the conflicts that arise from different projects competing for the same scarce resource are basically eliminated. On the other hand, it usually leads to an increase of capacity since certain scarce expertise has to be available at every project (ship). Therefore, such an approach in principle is only applicable to production environments of moderate technical complexity. Given the high technological complexity of modem warships and the decreasing budgets of the RNN, an overall grouptechnology approach appears to be a bridge too far. However, a temporary clustering of different expertises in one team to maintain large installations in a ship seems to be possible. Such a clustering still reduces the overall planning effort significantly. To be specific, in a capacity planning system such as the one introduced in Section 5, a set of jobs, all related to the overhaul or repair of one installation, may now be replaced by a single task, with the amount of capacity needed from each expertise group added to it. The current version of the capacity planning system is able to support such a limiled grouptechnological approach.

\section{Summary and conclusions}

The objective of this paper has been to present the basic structure of a reengineering process. To this end, we have discussed the production systems redesign process at the Royal Netherlands Naval Dockyard in some detail. The basic elements we encountered are: the analysis and a typology of the production syslem, changing objectives and constraints, a new production management structure, supporting planning tools and organisational changes.

An indispensible condition to make such a change process a success is a thorough commitment of all levels in the organisation. In that sense, the RNN Dockyard is a nice example. Not only the Dockyard's CEO and senior management, but also staff and employees of the departments (in particular Maintenance Engineering and Production) are definetely committed to the process. Al this point in time, a major effort is spent in filling the process planning database, to come up with a consistent set of standards for all activities. A shop floor scheduling system for a number of workshops is in use now, with very encouraging results. Several working groups are set up to further work out organisational consequences and improved coding systems. In conclusion, all conditions seem to be fulfilled to make the Dockyard an organisation which combines superb technical skills with an excellent logistic performance.

\section{References}

1. Hammer, M. and J. Champy [1993], Re-engineering the corporation: a manifesto for Business Revolution. Harper Collins,
2. Fogarty, D.W., J.H. Blackslone and Th. R. Hollmann [1991]. Production and Inventory Management, $2^{\text {md }}$ ed., South-Western Publishing Co.,

3. De Waard. A.J. [1995], A new production management model for the RNN Dockyard (in Dutch). Internal Report RNN.

4. Wight, O. [1984], Manufacturing Resources Planning: MRP II, Oliver Wight Lld.,

5. Groenestein, M.P. [1995], Process Planning at the RNN Dockyard (in Dutch), Inlernal Report RNN,

6. Adams, J., E. Balas and D. Zawack [1988]. The shifting bottleneck procedure for job shop scheduling. Management Science 34. pp. 391-401.

7. Zijm. W.H.M. [1995], The integration of process planning and shop floor scheduling in small batch pant manufacturing. Annals of the CIRP, 44/1, pp. 429-432.

8. De Boer, R.J. and W.H.M. Zijm [1995], Scheduling mulliprocessor lasks with precedence constraints and release and due dates, Working Paper, Department of Mechanical Engineering. University of Twente,

9. Clark. A.J. [1981], Experiences with a multiindentured, multi-echelon inventory model, in: L.B. Schwarz (ed.), Multi-level production/inventiony control systems: theory and practice, pp. 299-330, NorthHolland,

10. Burbidge, J.L. [1975], The introduction of group technology. Heineman,

11. Wiendahl, H.-P. and P. Scholtissek [1994]. Management and control of complexity in manufacturing. Annals of the CIRP, 43/2, pp. 1-8. 